\title{
CARACTERIZAÇÃO FíSICO-QUÍMICA E COMPOSIÇÃO CENTESIMAL E MINERAL DO FRUTO DO JUAZEIRO (Ziziphus joazeiro MART.)
}

\footnotetext{
TJosé Barros da Silva, ${ }^{2}$ Maria de Fátima Vitória Moura, ${ }^{3}$ Talita Raniely da Costa Silva, ${ }^{4}$ Nkarthe Guerra Araújo, ${ }^{5}$ Idiana de Macêdo Barbosa.

${ }^{1}$ Professor, Doutor em Química da Universidade Federal do Rio Grande do Norte, campus de Macaíba-RN (e-mail: barros@ufrnet.br).

${ }^{2}$ Professora, Doutora em Química do Instituto de Química da Universidade Federal do Rio Grande do Norte, campus central, Natal-RN.

${ }^{3}$ Discente do curso de Agronomia, Universidade Federal do Rio Grande do Norte, campus de Macaíba-RN.

${ }^{4}$ Mestre em Ciência e Tecnologia de Alimentos, Universidade Federal do Rio Grande do Norte, campus de Macaíba-RN.

${ }^{5}$ Graduada em Gastronomia, Universidade Federal do Rio Grande do Norte, campus de Macaíba-RN.
}

Recebido em: 08/04/2017 - Aprovado em: 10/06/2017 - Publicado em: 20/06/2017

DOI: 10.18677/EnciBio_2017A27

\begin{abstract}
RESUMO
O juazeiro (Ziziphus joazeiro Mart.), encontrado naturalmente nas áreas de caatinga do Nordeste brasileiro se apresenta como uma possibilidade de aproveitamento agroindustrial do seu fruto (juá), integrando uma das maiores diversidades de frutas regionais brasileiras, entretanto, há a necessidade de aprofundamento de estudos preliminares desta espécie no âmbito da sua caracterização para o uso alimentício. O objetivo deste trabalho é caracterizar o fruto do juazeiro sob o aspecto físicoquímico e da composição centesimal e mineral e avaliar a sua potencialidade agroindustrial com base, especialmente, em parâmetros físico-químicos (parte comestível, sólidos solúveis, acidez titulável e pH) Observou-se no fruto maduro um rendimento médio da parte comestível $(91,83 \%)$, teor de sólidos soluveis $\left(18,98^{\circ}\right.$ Brix), acidez titulável $(0,14 \%$ em ácido cítrico) e pH $(5,30)$. A análise centesimal foi fracionada em umidade $(79,01 \%)$, proteínas $(2,01 \%)$, lipídios $(0,52 \%)$, carboidratos $(17,59 \%)$, fibras $(0,11 \%)$ e cinzas $(0,76 \%)$. A partir das cinzas foi determinado o teor de minerais presentes. Os resultados da caracterização física, físico-química e da composição centesimal e mineral do juá maduro foram compatíveis com o perfil característico das frutas em geral, indicando, também, mostraram potencialidade desta espécie para o processamento agroindustrial.
\end{abstract}

PALAVRAS-CHAVE: composição, Juá, potencialidade agroindustrial. 


\title{
PHYSICAL-CHEMICAL CHARACTERIZATION AND CENTENAMIMAL AND MINERAL COMPOSITION AND CHEMISTRY OF JUAZEIRO FRUIT (Ziziphus joazeiro MART.)
}

\begin{abstract}
The juazeiro (Ziziphus joazeiro Mart.), Found naturally in the caatinga areas of the Brazilian Northeast, presents itself as a possibility of agroindustrial utilization of its fruit (juá), integrating one of the greatest Brazilian regional fruit diversities, however, there is a need for deepening of preliminary studies of this species in the scope of its characterization for the alimentary use. The present research presents as The objective of this work is to characterize the fruit of the juazeiro under the physicalchemical and chemical composition of the centesimal and mineral, and to evaluate its agroindustrial potential based mainly on physicochemical parameters ( soluble solids, titratable acidity and $\mathrm{pH})$. An average yield of the edible part $(91.83 \%)$, soluble solids content (18.98 ${ }^{\circ}$ Brix), titratable acidity $(0.14 \%$ in citric acid) and $\mathrm{pH}$ (5.30) was observed in the mature fruit. The centesimal chemical composition was fractionated in moisture $(79.01 \%)$, proteins $(2.01 \%)$, lipids $(0.52 \%)$, carbohydrates $(17.59 \%)$, fibers $(0.11 \%)$ and ashes $0.76 \%)$. From the ashes the mineral content was determined. The results of the physical, physicochemical and chemical composition of the centesimal and mineral mineral of the mature juá were compatible with the characteristic profile of the fruits in general, indicating, also, the potentiality of this species for agroindustrial processing.
\end{abstract}

.KEYWORDS: Juá, composition, agroindustrial potentiality.

\section{INTRODUÇÃO}

O juazeiro (Ziziphus joazeiro Mart) é uma planta típica da região semiárida brasileira, encontrado naturalmente nas áreas de caatinga, onde é conhecido popularmente como juá, joá-de-espinho, laranjeira de vaqueiro dentre outras denominações. Apresenta grande importância econômica e ecológica, sendo utilizado localmente para arborização de ruas e jardins, na medicina popular, na fabricação de cosméticos e na alimentação animal, especialmente em períodos de estiagens prolongadas (ALVES et al., 2008). No Brasil, o gênero Ziziphus está distribuído em todas as regiões, exceto no Sul do país, sendo que $Z$. joazeiro, embora típico da caatinga, consegue ultrapassar esse limite chegando a habitar algumas áreas menos secas (MONIZ, 2002).

O juá é uma drupa globosa de coloração amarelo-pardo, de 1,0 a 1,5 centímetros de diâmetro, com pedúnculos orlados e caroço envolto em uma polpa mucilaginosa, doce e branca, com elevados teores de vitamina C (SILVA et al., 2011). LIRA JÚNIOR et al. (2005) estudando outra espécie de fruta, naturalmente presente no ecossistema nordestino, afirmaram que os caracteres físicos dos frutos referentes à aparência externa, tamanho, forma e cor da casca, e as características físico-químicas relacionadas ao sabor, odor, textura e valor nutritivo, constituem atributos de qualidade à comercialização e utilização da polpa na elaboração de produtos industrializados.

Apesar de ser uma espécie bastante utilizada pela população do semiárido nordestino, a exploração do juazeiro limita-se ao extrativismo predatório, sendo necessários investimentos em estudos e pesquisas capazes de contribuir para a sua domesticação e cultivo (SOUSA et al., 2015), portanto, postando-se como alternativa 
de sustentabilidade da vida nessa região. Informações disponíveis sobre a caracterização do fruto do juazeiro fornecem alguns indicativos da possibilidade de diversificação do seu uso na alimentação humana, conforme resultados de MONIZ (2002) e OLIVEIRA et al. (2012), entretanto, há a necessidade de aprofundamento de estudos sobre esta espécie frutícola no âmbito da caracterização, físico-química e química, visando o seu aproveitamento como alimento. O presente trabalho teve por objetivo caracterizar o fruto do juazeiro por meio de análises físicas, físicoquímicas e químicas, tendo como foco avaliar a viabilidade para o processamento agroindustrial.

\section{MATERIAL E MÉTODOS}

Os frutos (juás), em estádios de maturação semi-maduro e maduro, foram coletados manualmente em juazeiros existentes na fazenda da Escola Agrícola de Jundiaí, município de Macaíba/RN. Após coleta o material foi acondicionado em sacos plásticos (polietileno). A higienização dos frutos incluiu as etapas de lavagem em água corrente, imersão em solução de hipoclorito de sódio (100ppm) durante 20 min, enxágue com água destilada e remoção do excesso de água por meio do uso de telas em nylon. Posteriormente, os juás foram divididos em porções de $1.500 \mathrm{~g} e$ acondicionados em sacos em polietileno e conduzidas ao laboratório de química analítica da UFRN para os procedimentos de análise,

\section{Caracterização físico-quími do fruto}

Foram realizadas medidas dos diâmetros, longitudinal (DL) e transversal (DT), com auxílio de paquímetro (marca Vernier) em amostras representativas de 30 frutos para cada estádio de maturação (semi-maduro e maduro). A firmeza foi determinada por meio de penetrômetro manual, modelo FT (3 - 27 lbf) com ponteira de $7 \mathrm{~mm}$ de diâmetro por meio de leitura na porção basal do fruto com a presença da casca. $O$ rendimento em polpa (parte comestível) foi determinado por diferença entre a massa (g) média dos frutos e dos caroços. Os frutos (1.000g cada porção) foram desintegrados em multiprocessador de bancada e após remoção dos caroços (sementes).O epicarpo (casca) do fruto foi pesado com a polpa, pois, é comestível e de difícil separação. Da polpa, foram extraídas as amostras, em triplicata, e realizadas as análises de sólidos solúveis, acidez titulável total e $\mathrm{pH}$, conforme as técnicas analíticas definidas pelo INSTITUTO ADOLFO LUTZ (2005).

\section{Análise centesimal do fruto}

Amostras retiradas da polpa em triplicata, também, foram submetidas às análises de umidade, proteínas, lipídeos, fibra bruta, carboidratos e cinzas.. As determinações foram executadas segundo as técnicas analíticas definidas pelo INSTITUTO ADOLFO LUTZ (2005).

\section{Composição mineral}

A partir das cinzas, foi determinado o teor de minerais presentes por meio do sistema de espectrometria de emissão ótica com plasma de argônio indutivamente acoplado (ICP-OES/Thermo Analítica). As cinzas foram umedecidas com 0,5 ml de água desmineralizada e dissolvidas em $5 \mathrm{ml}$ de uma solução de $\mathrm{HCl} / \mathrm{HNO}_{3}$ a $10 \%$ $(\mathrm{v} / \mathrm{v})$ e filtradas para balão volumétrico de $100 \mathrm{ml}$ e o volume completado com $\mathrm{HNO}_{3}$ a $5 \%(\mathrm{v} / \mathrm{v})$ para que as concentração de ácido seja igual a das soluções-padrão, conforme Brito (2010). As determinações de minerais no fruto in natura foram 
realizadas em uma única varredura, em triplicata, conforme a metodologia do INSTITUTO ADOLFO LUTZ (2005).

$\mathrm{Na}$ análise estatística de resultados da caracterização do fruto e na elaboração de gráficos foi utilizado o software R V3.0.2. As determinações foram realizadas em triplicata, e os resultados submetidos à análise de variância (ANOVA) a $5 \%$ de probabilidade.

\section{RESULTADOS E DISCUSSÃO}

\section{Caracterização físico-química do fruto}

A Tabela 1 e a Figura 1 apresentam os resultados da caracterização físicoquímica do fruto do juazeiro in natura em estádio de maturação semi-maduro e maduro. Os valores da razão $(0,95$ e 0,97$)$ entre diâmetros longitudinal (DL) e transversal(DT) (Tabela 1) indicam um formato arredondado dos juás, enquanto, frutos desta espécie analisado por ARAÚJO et al. (2015) apresentaram-se ovalados, com médias de comprimento e largura de 17,80 e 15,34 mm, respectivamente.

Os resultados referentes à firmeza mostram uma diferença de $3,14 \mathrm{lbf}$ favorável ao fruto semi-maduro. As substâncias pécticas, fortemente correlacionadas com firmeza, são os principais componentes químicos dos tecidos responsáveis pelas mudanças de textura das frutas e hortaliças em estado natural.

TABELA 1 - Parâmetros físico--químicos do fruto do juazeiro em estádio de maturação semi-maduro e maduro.

\begin{tabular}{lcccc}
\hline \multirow{2}{*}{\multicolumn{1}{c}{ Parâmetro }} & \multicolumn{4}{c}{ Estádio de Maturação } \\
\cline { 2 - 5 } & \multicolumn{2}{c}{ Semi-Maduro } & \multicolumn{2}{c}{ Maduro } \\
\cline { 2 - 5 } & Média & Dp & Média & Dp \\
\hline Diâmetro longitudinal (mm) & 15,00 & 1,03 & 17,25 & 1,83 \\
Diâmetro transversal (mm) & 15,85 & 1,31 & 17.85 & 1,73 \\
DL / DT & 0,95 & - & 0,97 & - \\
Firmeza* (Ibf) & 8,59 & 0,95 & 5,45 & 0,93 \\
Massa do fruto (g) & 4,13 & 0,41 & 5,19 & 0,72 \\
Massa do caroçO** (g) & 0,35 & 0,02 & 0,42 & 0,04 \\
Parte comestível (\%) & 91,43 & - & 91,83 & - \\
Sólidos solúveis totais - SST (' Brix) & 16,82 & 0,36 & 18,98 & 0,53 \\
Acidez titulável - AT & 0,15 & 0,03 & 0,14 & 0,01 \\
Relação SST/AT & 112,13 & - & 135,57 & - \\
pH & 4,85 & 0,06 & 5,30 & 0,02 \\
\hline
\end{tabular}

$\mathrm{Dp}=$ desvio padrão.

* Resistência da parte comestível à penetração; **Caroço = endocarpo + semente; 
À medida que os frutos amadurecem ocorre degradação das substâncias que determinam a sua rigidez, o que pode ser facilmente observado pelo amolecimento da polpa dos referidos alimentos (BORGUINI \& SILVA, 2005). Fruto do juazeiro (juá) colhido na região de Mossoró (RN) e observados por SILVA et al. (2011) apresentaram média geral de 5,99 lbf, sendo inferior aos valores verificados no fruto semi-maduro $(8,59 \mathrm{lbf}$ e superior ao fruto maduro $(5,45)$ avaliados no presente trabalho (Tabela 1). A medição da firmeza do fruto com a casca(epicarpo), certamente, influencia para mais os valores deste parâmetro.

Os diâmetros (DL e DT) dos frutos (Tabela 1) submetidos à análise estatística, , ao nível de 5\% de significância, evidencia diferença entre os frutos semi-maduros e maduros (Tabela 2).

TABELA 2 - Análise comparativa entre os diâmetros longitudinal (DL) e transversal (DT) do fruto do juazeiro semi-maduro e maduro.

\begin{tabular}{lcccc}
\hline Diâmetro & \multicolumn{4}{c}{ Estágio de Maturação } \\
\cline { 2 - 5 }$(\mathrm{mm})$ & Semi-Maduro & Dp & Maduro & Dp \\
\hline Longitudinal & $15,00^{\mathrm{a}}$ & 1,03 & $17,25^{\mathrm{b}}$ & 1,83 \\
Transversal & $15,85^{\mathrm{a}}$ & 1,31 & $17.85^{\mathrm{b}}$ & 1,73 \\
\hline Dp = Desvio padrão \\
Letras diferentes em uma mesma linha indicam diferença estatística. \\
(Tukey a 5\%). \\
Fonte: Próprio autor.
\end{tabular}

Observou-se, também, diferença entre as médias dos grupos semi-maduro e maduro relativo à sua massa comestível (Figura 1), resultando, portanto, em maior proporção de polpa no fruto com maduração plena. Na fase de desenvolvimento e maturação dos frutos os componentes físicos e químicos sofrem mudanças qualitativas e quantitativas acentuadas, tais como, mudança na coloração e acréscimo de açúcares e outros compostos (MONIZ, 2002).

A Figura 1 apresenta, de forma gráfica, as massas do fruto e do caroço e a massa comestível ( $\mathrm{g}$ ) do juá semi-maduro e maduro. O epicarpo compõe a parte (comestível) do fruto, não sendo destacado na forma de casca quando consumido como alimento. 

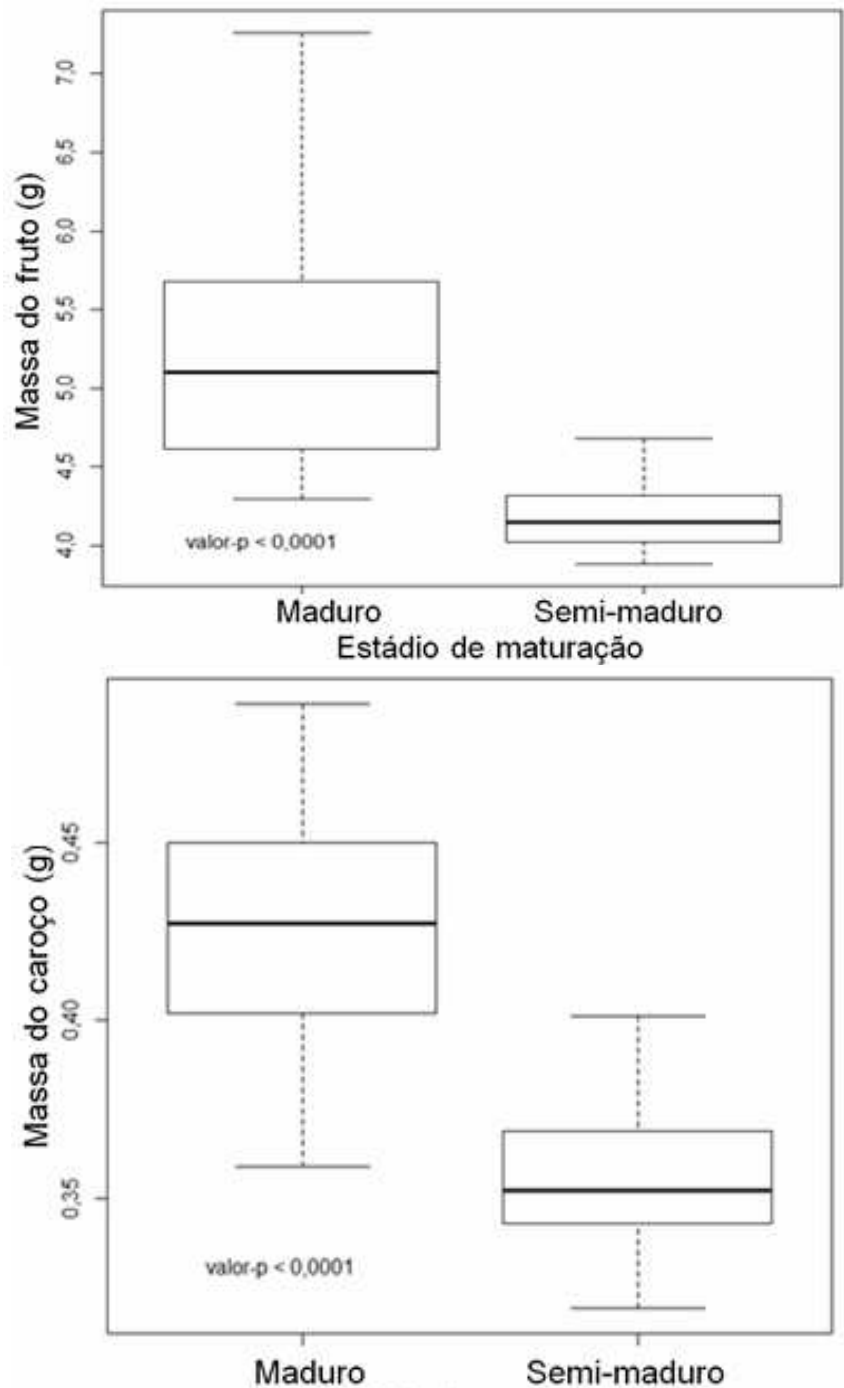

Estádio de maturaçăo

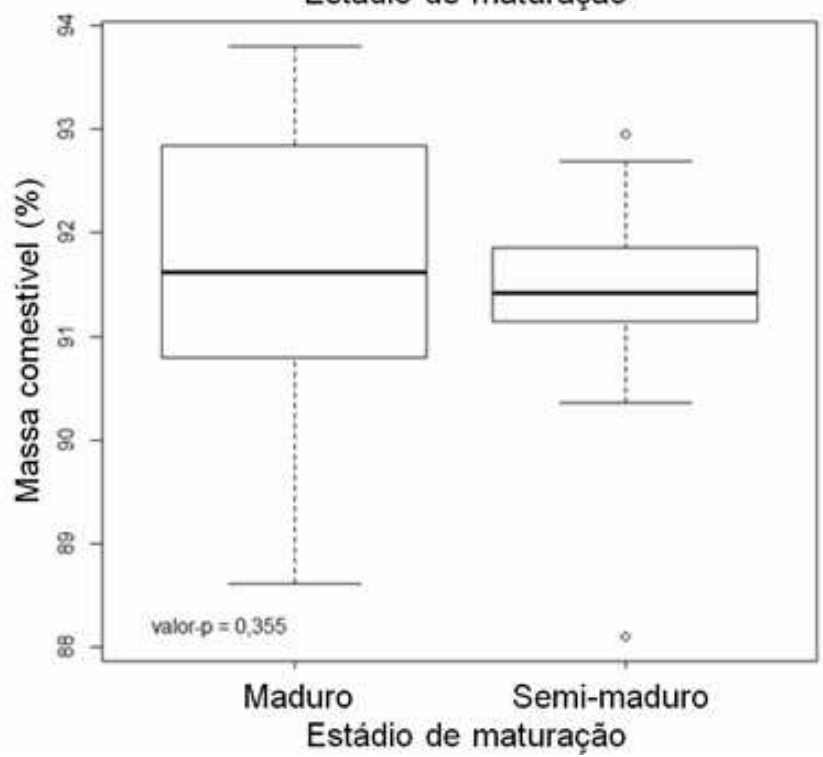

FIGURA 1 - Massa do fruto, caroço e a da massa comestível ( $\mathrm{g}$ ) do juá semi- maduro e maduro (Fonte: Dados da pesquisa). 
$\mathrm{Na}$ avaliação da massa comestível do fruto (Figura 1), ao nível de $5 \%$ de significância, pode-se afirmar que não há diferença entre as médias dos grupos semi-maduro e maduro em relação a este parâmetro. Os resultados da caracterização físico-química (Tabela 1) mostram que os valores da acidez titulável (AT), em ácido cítrico, $0,14 \%$ no fruto maduro e $0,15 \%$ no fruto semi-maduro se aproximam da média dos resultados $(0,13 \%)$ obtidos por Silva et al.(2011) em frutos de juazeiro colhidos no município de Mossoró-RN e superior ao resultado $(0,016 \%)$ apresentado por MONIZ (2002) em amostras de frutos colhidos em Tanquinho-BA.

Os teores de sólidos solúveis totais (SST), representados por grau Brix observados em fruto semi-maduro $\left(16,82^{\circ}\right.$ Brix) e maduro $\left(18,98^{\circ}\right.$ Brix) estão acima dos valores mínimos definidos na legislação (BRASIL, 2000) para a polpa de

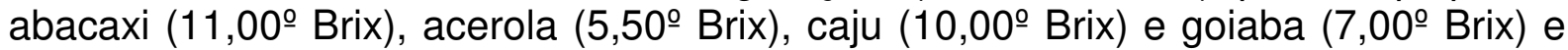
dos valores médios verificados em umbu-cajá (11,25 Brix), umbu $\left(10,60^{\circ}\right.$ Brix), goiaba (8,89을 Brix), respectivamente, por LIRA JUNIOR et al. (2005), CAMPOS (2007) e SILVA et al. (2009).

SOUSA et al. (2015) observaram valores de sólidos solúveis totais (SST) correspondentes a $29,3^{\circ}$ Brix em polpa de juás colhidos no município de Sobral-CE. Os SST, normalmente, se elevam com o avanço da maturação, enquanto a AT é reduzida, sendo assim, a relação SST/AT é diretamente proporcional aos SST e inversamente a AT. A relação SST/AT é mais representativa que a medição isolada de açúcares ou acidez, pois a relação confere o equilíbrio entre esses componentes (CHITARRA e CHITARRA, 2005). Resultados obtidos por SSILVA et al. (2011) e SOUSA et al. (2013) em juás colhidos na região de Mossoró/RN indicaram valores médios da relação SST/AT iguais a 132,24 e 127,39, respectivamente.

Os valores de $\mathrm{pH}$ e da acidez titulável observados na polpa do juá, em ambos estágios de maturação (Tabela 1), são superiores e inferiores, respectivamente, aos resultados de SOUSA et al. (2013), que determinaram o pH igual a 4,64 e a acidez titulável equivalente a $0,23 \%$ em polpa de frutos maduros, desta espécie, obtida por despolpamento industrial.

\section{Análise centesimal e composição mineral do fruto maduro}

$\mathrm{Na}$ análise centesimal foi considerado, particularmente, o fruto maduro (Tabela 3). Avaliando-se a composição química dos juás é possível comprovar as maiores frações para a umidade e carboidratos e as menores para os teores de proteínas, lipídeos, fibras e cinzas, indicando, portanto, um perfil nutricional característico da grande maioria das frutas, extrativas ou cultivadas. Ressalta-se, porém, que o teor de carboidrato $(17,59 \%)$ observado está acima do teor do açaí $(6,2 \%)$, acerola $(8,0 \%)$, azeitona verde $(4,1 \%)$, caju $(10,3 \%)$, umbu $(9,4 \%)$, goiaba $(13,0 \%)$, Jamelão $(10,6 \%)$, confrontando-se estes valores com a Tabela Brasileira de Composição de Alimentos - Taco (UNICAMP, 2011).

TABELA 3 Análise centesimal do fruto do juazeiro (Ziziphus joazeiro Mart).

\begin{tabular}{lcc}
\hline Parâmetro & $\begin{array}{c}100 \times \mathrm{xg}^{-1} \\
\%\end{array}$ & $\mathrm{Dp}$ \\
\hline Umidade & 79,01 & 0,68 \\
Proteínas & 2,01 & 0,10 \\
Lipídios & 0,52 & 0,06 \\
Fibras & 0,11 & 0,00 \\
Carboidratos & 17,59 & 0,56 \\
Cinzas & 0,76 & 0,06 \\
\hline
\end{tabular}

$\mathrm{Dp}=$ desvio padrão 
As cinzas variam de 0,4 a $2,1 \%$ em frutas frescas e representam os minerais contidos nos alimentos que podem estar em grandes quantidades como o potássio, sódio e cálcio e pequenas quantidades como o ferro, manganês, magnésio e zinco (CORREIA et al., 2011). O teor de minerais presentes nas cinzas do fruto do juazeiro está apresentado na Tabela 4. Dos nove minerais contemplados na Taco (UNICAMP, 2011), à exceção do fósforo, todos foram determinados na parte comestível do fruto.

TABELA 4 - Teor de minerais do fruto do juazeiro (Ziziphus joazeiro Mart).

\begin{tabular}{ccc}
\hline Mineral & $\mathrm{mg} 100 \mathrm{~g}^{-1}$ & $\mathrm{Dp}$ \\
\hline Cálcio & 18,921 & 1,256 \\
Cobalto & 0,000 & 0,000 \\
Cobre & 0,007 & 0,001 \\
Cromo & 0,002 & 0,000 \\
Ferro & 0,043 & 0,000 \\
Magnésio & 16,911 & 1,008 \\
Manganês & 0,032 & 0,001 \\
Molibdênio & 0,002 & 0,000 \\
Níquel & 0,003 & 0,000 \\
Potássio & 165,289 & 13,041 \\
Selênio & 0,006 & 0,000 \\
Sódio & 6,939 & 0,452 \\
Zinco & 0,147 & 0,002 \\
\hline
\end{tabular}

$\mathrm{Dp}=$ desvio padrão

As frutas são consideradas do ponto de vista do seu valor nutritivo complementos importantes no fornecimento de minerais da alimentação e, sob este aspecto, o fruto do juazeiro apresentou o teor de cálcio $\left(18,92 \mathrm{mg} 100 \mathrm{~g}^{-1}\right)$ aproximado ao obtido no araçá $\left(21,0 \mathrm{mg} 100 \mathrm{~g}^{-1}\right)$, superior ao da cagaita $(8,0 \mathrm{mg} 100$ $\mathrm{g}^{-1}$ ) e ao do caju do cerrado $\left(15,0 \mathrm{mg} 100 \mathrm{~g}^{-1}\right)$ e inferior ao do araticum (29 mg $100 \mathrm{~g}$ $\left.{ }^{1}\right)$, da mangaba (35,0 mg $\left.100 \mathrm{~g}^{-1}\right)$ e da pitomba $\left(27,7 \mathrm{mg} 100 \mathrm{~g}^{-1}\right)$ em comparação aos dados obtidos por REIS SILVA et al. (2008) em frutas nativas brasileiras.

No tocante ao teor de potássio (165 mg $100 \mathrm{~g}^{-1}$ ), o juá foi superior aos resultados publicados na Taco (UNICAMP, 2011) para o açaí (124 mg $100 \mathrm{~g}^{-1}$ ), caju (124 mg $100 \mathrm{~g}^{-1}$ ) e azeitona preta em conserva $\left(79 \mathrm{mg} 100 \mathrm{~g}^{-1}\right)$. Igualou-se à acerola (165 mg $100 \mathrm{~g}^{-1}$ ) e foi inferior à seriguela (248 mg $\left.100 \mathrm{~g}^{-1}\right)$, goiaba (198 mg $\left.100 \mathrm{~g}^{-1}\right)$, jamelão (394 mg $100 \mathrm{~g}^{-1}$ ) e a banana nanica (376 mg $100 \mathrm{~g}^{-1}$ ), sendo esta última, uma fonte de referência deste mineral (potássio).

\section{CONCLUSÃO}

Os resultados da caracterização físico-química, da análise centesimal e composição mineral do fruto do juazeiro maduro indicaram potencialidades desta espécie nativa para o processamento agroindustrial, representando, portanto, uma alternativa para a elaboração de alimentos a ser explorada no Nordeste brasileiro de uma forma sustentável. 


\section{REFERÊNCIAS.}

ALVES, E. U.; BRAGA JÚNIOR, J. M.; BRUNO, R. L. A., OLIVEIRA, A. P.; CARDOSO, E. A.; ALVES, A. U.; ALVES, A. U.; SILVA, K. B. Métodos para quebra de dormência de unidades de dispersão de Ziziphus joazeiro Mart. Revista Árvore, v.32, n.3, p. 407-415, 2008.

ARAÚJO, B. A. M. C.; BARBOSA DA SILVA; MOREIRA, F. J. C.; SILVA, K. F.; TAVARES, M. K. N. Caracterização biométrica de frutos e sementes, química e rendimento de polpa de juazeiro (Ziziphus joazeiro Mart.). ACSA - Agropecuária Científica no Semi-Árido, v. 11, n. 2, p. 15-21, 2015.

BORGUINI, R. G.; SILVA, M. V. Características físico-químicas e sensoriais do tomate (Lycopersicon esculentum) produzido por cultivo orgânico em comparação ao convencional. Alim. Nutr., Araraquara, v.16 n.4, p. 355-361, 2005.

BRASIL. Ministério da Agricultura e do Abastecimento. Instrução Normativa n. 01 (polpa de frutas) de 7 de janeiro de 2000. Diário Oficial da União, Brasília, 10 de janeiro de 2000.

BRITO, G. Q. Espectrometria de emissão óptica com plasma indutivamente acoplado aliada à quimiometria na determinação de íons metálicos no molusco Mytella falcata para discriminação de estuários potiguares. 2010. 164 f. Tese (Doutorado em química). Universidade Federal do Rio Grande do Norte, Natal/RN.

CAMPOS, C. O. Frutos de umbuzeiro (Spondias tuberosa Arruda): características físico-químicas durante o seu desenvolvimento e na pós-colheita. 2007. 213 f. Tese (Doutorado em Agronomia). Faculdade de Ciências Agronômicas, Botucatu-SP, 2007.

CORREIA, A. A. S.; GONZAGA, M. L. C.; AQUINO, A. C.; SOUZA, P. H. M.; FIGUEIREDO, R. W. MAIA, G. A. Caracterização química e físico-química da polpa do noni (Morinda citrifolia) cultivado no estado do Ceará. Araraquara: Alim. Nutr., v. 22, n. 4, p. 609-615, 2011.

IAL- INSTITUTO ADOLFO LUTZ. Métodos químicos e físicos para análise de alimentos. 4 ed. São Paulo: 2008. 1018 p.

LIRA JÚNIOR, J. S.; MUSSER, R. S.; MELO, E. A.; MACIEL, M. I. S., LEDERMAN, I. E.; SANTOS V. F. Caracterização física e físico-química de frutos de cajá-umbu (Spondias spp.). Ciência e Tecnologia de Alimentos., v. 25, n. 4, p. 757-761, 2005. MONIZ, K. L. A. Caracterização morfológica de sementes e frutos e estudos da germinação da espécie Ziziphus joazeiro Mart (Rhamnaceae). 2002. 88 f. Dissertação (Mestrado em botânica) - Universidade Estadual de Feira de Santana, Feira de Santana-BA, 2002.

OLIVEIRA, A. K.; COELHO. M. F. B.; MAIA, S. S. S.; DIÓGENES, F. E. P.; MEDEIROS FILHO, S. Atividade alelopática de extratos de diferentes partes de juazeiro (Ziziphus joazeiro Mart. - Rhamnaceae). Acta botânica Brasileira, v. 26, n.3, 685-690. 2012. 
REIS SILVA, M.; LACERDA, D. B. C. L.; SANTOS, G. G.; MARTINS, D. M. O. Caracterização química de frutos nativos do cerrado. Ciência Rural, v. 38, n.6, p. 1790-93, 2008.

SILVA, L. R.; BARRETO, N. D. S.; BATISTA, P. F.; ARAÚJO, F. A. R.; MORAIS, P. L. D. Caracterização de frutos de cinco acessos de juazeiro (Ziziphus joazeiro Mart.). Revista Brasileira de Produtos Agroindustriais, v.13, n.1, p. 15-20, 2011.

SOUSA, F. C.; SILVA, L. M. M.; CASTRO, D. S.; NUNES, J. S.; SOUSA, E. P. Propriedades e físico-químicas da polpa de juazeiro. Revista Verde, v.8, n.2, p. 6871, 2013.

UNICAMP - Núcleo de estudos e pesquisas em alimentação. Tabela brasileira de composição de alimentos (TACO), versão 3, Campinas: UNICAMP, 2011. 105 p. 